\title{
Compressive Strength of Construction Materials Containing Agricultural Crop Wastes: A Review
}

\author{
Nik Nadia Amira Nik $\mathrm{Pa}^{1}$, Mohd Haziman Wan Ibrahim ${ }^{1,}$, , Abdul Halim Abdul Ghani, \\ Ahmad Zurisman Mohd $\mathrm{Ali}^{1}$, and Mohd Fadzil Arshad ${ }^{2}$ \\ ${ }^{1}$ Jamilus Research Centre, Faculty of Civil and Environmental Engineering, Universiti Tun Hussein \\ Onn Malaysia, 86400, Parit Raja, Batu Pahat, Johor, Malaysia \\ ${ }^{2}$ Institute For Infrustructure Engineering and Sustainable Management, Universiti Teknologi MARA, \\ 40450, Shah Alam, Selangor, Malaysia
}

\begin{abstract}
The growth of industrialization and development of urban life made an increase in demand for cement, concrete and bricks. Exploitation on the non-renewable natural resources for raw materials will keep increased in order to meet the demands for construction materials. At the same time, the problems regarding the agricultural crop wastes such as rice husk, sugarcane bagasse, palm oil fuel waste and elephant grass has become an important issue nowadays. Consequently, there are many researchers who have been studying the viability of using these agricultural wastes as construction materials to meet the industry demands in order to decrease the current use of non-renewable natural resources. This paper reviewing on how agricultural waste could be utilized as replacement materials for construction activities from various researchers. The idea of using agricultural crop wastes was promoted by studying upon their engineering properties. This paper focusing on the compressive strength of the construction materials containing agricultural crop wastes, which was the common parameter considered by most researcher as required by various standards.
\end{abstract}

\section{Introduction}

The world's demand for cement until the first half of the $21^{\text {st }}$ century is expected to increase by about $2.5-5.8 \%$ every year [1]. Therefore, the exploitation on raw materials from non renewable natural resources were required in large quantities to meet the worldwide demand. At the same time, the cement and concrete productions has been an environmental issue since this industry contributed about $7 \%$ of carbon dioxide emission worldwide along with great consumption of energy and aggregate amount [2]. The usage of waste materials for variety of applications in construction industry kept increase due to the growing awareness of environmental issues and resource scarcity. Many industries take a step to find new materials from renewable resources to replace the current used materials derived from non-renewable resources due to strict legislative policies enforcement and in the same

* Corresponding author: haziman@uthm.edu.my 
time will protect the environment [3]. The productions and usage of agricultural wastes such as rice husk, sugarcane bagasse and straw, palm oil fuel shell, wheat straw, and elephant grass (Pennisetum Purpureum) have been successfully recycled in many products and being a great interest in many publications. The alternatives regarding utilization of agricultural waste to supply the demand for concrete and other construction materials has promote a breakthrough to make the construction industry more environmentally friendly and sustainable [2]. The wide availability of agricultural wastes makes them a suitable and dependable alternative for construction materials such as pozzolans, aggregate, and fibres [4]. Recycling the agricultural wastes will decrease the exploitation on natural resources, contributes to energy saving, and a reduction in the cost of construction materials but still can meet the current demands. It also solves the disposal problem of the wastes which saves landfill space, and hence, helps environmental protection $[5,6]$.

\section{Review of previous research on utilization of agricultural waste materials}

The agricultural crop waste materials discussed in this paper were rice husk, elephant grass (Pennisetum Purpureum), sugarcane bagasse, and palm oil fuel wastes, as detailed below. Compressive strength of products containing these waste materials was the parameter highlighted in this paper.

\subsection{Rice husk}

Rice husk is the byproducts which produced after milling process of paddy [7]. Rice husk being disposed and burned in open spaces due to zero commercial value, hence inviting serious environmental problems [8]. In certain country, rice husk was recycled as boiler fuel to generate electricity and steam but contribute about $20 \%$ of ash after incineration process [9]. With the proper preparations, rice husks can be processed to be ash and being used as pozzolans and filler in many construction application [10]. High content of amorphous silica $\left(\mathrm{SiO}_{2}\right)$ and large surface area contibuted to the high pozzolanic properties and good reactivity of the rice husk ash. In addition, the reactivity of rice husk ash can be improved by increasing its fineness. Recently, many researchers have studied the utilization of rice husk ash as pozzolans and filler in construction material [7,11-21].

Bie et al. [11] conducted a research regarding the mechanical behavior of cement mortar containing RHA burned at different burning conditions in muffle furnace. Cement mortar samples sized of $40 \times 40 \times 160 \mathrm{~mm}$ were prepared by replaced $0 \%, 5 \%, 10 \%$ and $20 \%$ of cement with RHA to obtain their compressive and flexural strength. It was proved that $10 \%$ of replacement ratio (by weight) of RHA has the best enhancement effect in compressive and flexural strength of the cement mortar. The result obtained shows that burning conditions can affect the specific surface area and properties of RHA in which $600{ }^{\circ} \mathrm{C}$ was the appropriate temperature to produce RHA with large specific surface area due to existence of amorphous silica and also decrease in potassium content. Bakar et al. [7] investigated the effects of RHA fineness on the chemical and physical properties of concrete using eight different fineness grades of RHA. The compressive strength and strength activity index of concrete sample blended with $15 \%$ by weight of RHA ground for 90 minutes (median particle size of $9.52 \mu \mathrm{m}$ ) has significantly increased. Similarly, Antiohos et al. [12] studied about the effectiveness of rice husk ash as reactive silica and its fineness in mortar and concrete. The results showed that the reactivity of RHA in the mortar and concrete increased when the fineness increased. Hwang et al. [13] studied the strength and durability characteristics of concrete incorporating $0 \%, 10 \%, 20 \%$ and $30 \%$ 
replacement ratio of cement by 1 hour ground RHA. The results indicated $20 \%$ ground RHA added to concrete has an equivalent values of compressive strength to control samples after 28 days and increased after 91 days of curing period. Eventhough it was possible to produce RHA blended concrete that has similar or better properties than ordinary concrete (without RHA), at least the study agreed that it can reduce the carbon dioxide emission when the level of cement consumptions is decreased. The same pattern were agreed by Shahidan et al [14] in which RHA replacement can increased the compressive strength of concrete after 28 days of curing period due to pozzolanic reactions.

A research conducted by Vishwakarma et al. [15] was a usage of RHA in nano size on the mechanical and microstructural properties of concrete. The RHA was prepared by burned the rice husk at temperature of $600^{\circ} \mathrm{C}$ to $800^{\circ} \mathrm{C}$ before being sieved and ground in a ball mill for an hour to get desired nanoparticle size (50 to 70 nanometer). It was found that RHA concrete have higher compressive, tensile and flexural strength than fly ash concrete due to the presence of nanosilica as nanosilica from RHA increased the polymerized layer structure and rough surface texture which increased the bonding between aggregates and cement paste. Meanwhile, a study regarding the usage of $15 \%$ of RHA both in natural conditions (without prior treatment or grinding) and ground RHA on the concrete properties was conducted by Zerbino at al. [16]. It was found that natural RHA can reduced the amount of cement content but required an optimization process to obtain acceptable particle size since the raw material contained a residue. Ground RHA provided an excellent characteristics in the fresh state and increased the mechanical properties of concrete even when blended with $25 \%$ of RHA. The concrete containing $15 \%$ of natural RHA showed similar mechanical and durability properties with that control concrete however the concrete with ground rice husk ash gave better results. The study proved that the usage of natural RHA in concrete was a good option to dispose this residue even without the prior treatment and grinding process.

Other than that, Kishore et al. [17] studied the strength characteristics of high strength concrete containing RHA and found that the replacement of cement with RHA decreased the compressive strength but achieved the strength target at $10 \%$ replacement for both of two different concrete grades (M40 and M50). Meanwhile, Tuan et al. [18] investigated the potentials of the usage of RHA to produce ultra-high performance concrete. It was found that RHA addition which less than $30 \%$ does not significantly decreased the compressive strength of ultra-high performance concrete compared to sample containing silica fume. This results was due to the fineness of RHA that has a positive effect on the compressive strength of ultra-high performance concrete and the optimum mean size for RHA was $5.6 \mu \mathrm{m}$. This study suggested that the cement comsumption can be replaced up to $40 \%$ with combination of silica fume and RHA in order to produce ultra high performance concrete.

Chopra et al. [19] investigated the effects of cement replacement with RHA as supplementary cementitious materials in self-compacting concrete (SCC) by replacing cement content with RHA by $0 \%, 10 \%, 15 \%$ and $20 \%$. The mechanical and durability properties of casted samples being tested after 7, 28 and 56 days of curing period. The results indicated that the compressive and tensile strength increased with the increasing of RHA content. The increasing of compressive strength of concrete was developed from the increasing formation of calcium silicate hydrate (C-S-H) gel which makes its structure dense. The optimum content of RHA replacement was found to be $15 \%$. Hesami et al. [20] studied the usage of RHA as cement replacement material in pervious concrete pavement in order to strengthen pozzolanic cement paste. A concrete mixture with $0 \%, 2 \%, 4 \%, 6 \%$, $8 \%, 10 \%$ and $12 \%$ weight percentages of RHA ash were prepared for physical and mechanical properties evaluation. The RHA used in the testing was burned in a furnace for 2 hours which produced black rice husk ash and then it was burned again in a special furnace to decarbonize the carbon content. This process increase the specific surface area 
and pozzolanic properties of rice husk ash. The results obtained shows that compressive, tensile and flexural of pervious concrete samples mixed with RHA were positively increased and found that $12 \%$ of RHA was the optimum content to for concrete pavements. The strength of concrete decreased after the optimum amount of RHA reached. In another study conducted by Jaya et al. [21] found that $40 \%$ of RHA as cement replacement in concrete improved resistance to seawater attack and effectively decreased ettringite and gypsum formations.

The possibilities of using rice husk and RHA in production of bricks as alternatives in recycling the waste materials was studied by Sutas et al. [22]. The bricks were produced by adding between rice husk and RHA which varied from $0 \%$ to $10 \%$ by weight into the clay mixtures. The results indicated that the main component of RHA was made up of silicon oxide in which contributed to the brick's strength while the aluminium and iron oxide changed the brick's color into red after sintering. It was found that the compressive strength and density of the brick can be increased with $2 \%$ of RHA addition.

\subsection{Pennisetum Purpureum}

Pennisetum Purpureum or known as elephant grass or Napier grass is a quick growing plant and has a production of about 40 ton/ha/year [23,24]. The Pennisetum Purpureum grass have reasonable energy content and higher calorific value fuels also categorized as biomass materials [25]. At the present, Brazil has been used 100\% of Pennisetum Purpureum grass as a renewable energy source in several thermoelectric power plant in their country which deposited a large quantities of ashes during direct burning process resulting in environmental problems [23,25]. The extraction of ortho-silicic acid from ground water by the Pennisetum Purpureum grass has made the plant contained considerable content of amorphous silica, which made it has pozzolanic properties similar to rice husk and sugarcane bagasse $[23,25]$. Researchers also conducted the possibility of fiber productions from Pennisetum Purpureum grass [26-28].

A laboratory scale study conducted by Nakanishi et al. [29] in which regarding the usage of Pennisetum Purpureum ash to manufacture eco-friendly binary cements. Pennisetum Purpureum ash were prepared through same process conducted by Nakanishi et al. [25]. The physical and mechanical of blended cement paste with $20 \%$ replacement of cement with Pennisetum Purpureum ash were evaluated after 28, 60 and 90 days of curing period. The study found that the cement paste containing $20 \%$ of Pennisetum Purpureum ash have similar strength with the control paste and cement paste containing $20 \%$ of silica fume after 90 days of curing period. Similarly, the same facts agreed by Nakanishi et al. [25] in which the main hydrated phases during the pozzolanic reaction in Pennisetum Purpureum paste consisted of C-S-H gels similar to silica fume paste. The study agreed that Pennisetum Purpureum ash can be cementitious materials as an alternative to traditional pozzolans. Meanwhile, Cordeiro and Sales [23] studied the pozzolanic properties of Pennisetum Purpureum ash and its effects on the mechanical properties of concrete. Pennisetum Purpureum ash was produced by three different method and laboratory scale tests were conducted to evaluate the physical and chemical properties of the Pennisetum Purpureum ash including the pozzolanic and reactivity test on the Pennisetum Purpureum ash paste. For the mechanical properties testing, a concrete sample with $20 \%$ replacement of cement with Pennisetum Purpureum ash were prepared. The results showed no changes in compressive strength, Young's modulus and water absorption rate of concrete containing $20 \%$ of Pennisetum Purpureum ash when compared to control sample and proved that the pozzolanic activity of Pennisetum Purpureum ash maintained the mechanical properties of concrete. 
Merta and Tschegg [30] studied the potentials usage of outer core of the Pennisetum Purpureum stem as fibres reinforcement for concrete. The study shows that Pennisetum Purpureum fibres had tensile strength of about 40 to $60 \mathrm{MPa}$, which has similar range to wheat straw fibres strength. On the other hand, Haameem et al. [25] investigated the mechanical properties of Pennisetum Purpureum (Napier) used as fibre or polyester composites. The extraction of Pennisetum Purpureum fibres were done through water retting process and then the fibres were alkali treated using sodium hydroxide $(\mathrm{NaOH})$ solutions. The study found that alkali treated fibres has higher strength than untreated fibres and $10 \%$ alkali treated fibres showed highest tensile strength. The tensile and flexural strength of Pennisetum Purpureum fibres composites increased with the increasing of fibres volume fractions. It was found that $25 \%$ of volume fraction of Pennisetum Purpureum fibres showed optimum tensile and flexural strength. Futhermore, the research conducted by Ramaniah et al. [27] and Ridzuan et al. [28], both agreed that Pennisetum Purpureum fiber were suitable to be utilized as composites material in many applications due to its properties which were light in weight, have economic value and good thermal insulating properties.

\subsection{Sugarcane bagasse}

Sugarcane bagasse is a waste produced from extraction of sugarcane for sugar and alcohol production industry [31]. Approximately, $1 \mathrm{~kg}$ of sugarcane produced $25 \%$ of bagasse and $0.6 \%$ of bagasse ash [32]. After combustion process, the sugarcane residue dominated by silicon dioxide $\left(\mathrm{SiO}_{2}\right)$ in chemical composition [33]. Disposal problems arises due the high volume of the sugarcane residue, in which turning this ash as a pozzolanic material in the construction sectors would be a suitable disposal way [31].

Tashima et al. [34] studied on the utilization of sugar cane straw ash in blended cement as pozzolans. The microstructural characteristics and mechanical strength were evaluated onto cement paste and cement mortar containing sugarcane straw ash. The results obtained shows a positive development on compressive strength of mortar containing $15 \%$ to $30 \%$ of sugarcane straw ash. After 28 and 90 days, mortar samples containing $25 \%$ and $30 \%$ of sugarcane straw ash given same results with the control sample in which, indicated that the sugarcane straw ash has a potential to be used as pozzolanic admixture in blended mortars with high replacement levels. Rukzon and Chindaprasirt [35] carried out the investigation on utilization of finely ground bagasse ash as a pozzolanic material in high strength concrete. The concrete samples were prepared by replacing the cement content with $10 \%$, $20 \%$ and $30 \%$ of bagasse ash. The concrete samples showed good strength and low porosity when $10 \%$ of bagasse ash was used. From the study, it was concluded that the high strength concrete can be produced by replacing the cement with $30 \%$ of bagasse ash. On the other hand, an investigation on the strength and durability properties of concrete containing $10 \%$, $20 \%, 30 \%, 40 \%$ and up to $50 \%$ of ground bagasse ash by weight of binder were conducted by Rerkpiboon et al. [36]. The study found that the highest compressive strength of concrete was achieved at $20 \%$ of replacement cement by bagasse ash at 90 days age.

Modani and Vyawahare [37] conducted a research on the usage of sugarcane bagasse ash as a partial replacement of fine aggregate in concrete. The concrete samples were casted using untreated sugarcane bagasse ash with replacement ratio of $0 \%, 10 \%, 20 \%, 30 \%$ and $40 \%$ by volume of fine aggregate. The results indicated that the usage of untreated sugarcane bagasse ash as fine aggregate does not give any decrease in workability and strength of concrete. The compressive strength of concrete containing $10 \%$ and $20 \%$ of sugarcane bagasse ash increased due to pozzolanic reaction after 28 days of curing period. Lima et al. [38] studied the potentials of compressed earth brick block masonry (CEB) containing sugarcane bagasse through their mechanical properties. Two sets of blocks with 
$6 \%$ and $12 \%$ cement addition were prepared while the sugarcane bagasse ratio added to the blocks were $0 \%, 2 \%, 4 \%$ and $8 \%$ for each mixture. The results found that satisfactory compressive strength were achieved by the block containing $12 \%$ of cement while the addition of sugarcane bagasse ash did not affect the mechanical strength and water absorption of the CEB. However, the block prepared with $12 \%$ of cement and $8 \%$ of sugarcane bagasse ash have potentials to be used as non-structure masonry component. Montes-Garcia et al. [39] analyzed the use of lime and sugar cane bagasse ash (SCBA) as chemical stabilizers in compacted soil blocks. The results indicate that blocks manufactured with $10 \%$ of lime in combination with $10 \%$ of SCBA showed better performance than those containing only lime.

\subsection{Palm oil fuel waste}

Malaysia, Indonesia, Thailand and Nigeria has become most important agro-industries for oil palm products with Malaysia as the world's largest producer and exporter of palm oil [40]. One of the problems in the palm fruit processing plants is that the process produces large quantities of solid waste resulting in pollution problems [41]. The production of solid waste from the palm oil industry in Malaysia, Indonesia and Thailand was 47, 40 and 3.5 million tons per year, respectively. The solid wastes include oil palm bunches, palm fibres and fruit shells.

Alsubari et al. [42] studied the usage of treated palm oil fuel as supplementary cementitious material (SCM) to produce sustainable self-compacting concrete (SCC). A laboratory scale study were conducted by preparing the concrete mixtures with $0 \%, 50 \%$, $60 \%$ and $70 \%$ replacement of cement with treated palm oil fuel ash. The treated palm oil fuel ash SCC has lower compressive strength at early age however, still can be classified as high strength class at 1 day age. SCC blended with $50 \%$ to $70 \%$ of treated palm oil fuel ash showed similar compressive strength to control SCC and kept increased after 28 days. Tangchirapat et al. [43] investigated the effects of ground palm oil fuel ash utilization as pozzolanic material in high strength concrete by replacing the cement content at $10 \%, 20 \%$ and $30 \%$. The results indicated that ground palm oil fuel ash with high fineness suitable to be used as pozzolans to produce high strength concrete with $20 \%$ of replacement. Overall, $20 \%$ replacement of ground palm oil fuel ash in high strength concrete mixture has smaller loss in compressive strength compared to high strength concrete made from other type of Portland cement. Muthusamy et al. [44] carried out a study on the production of oil palm shell lightweight aggregate concrete containing palm oil fuel ash. The results indicated that desired compressive strength of oil palm shell lightweight aggregate concrete can be achieved through $20 \%$ replacement of palm oil fuel ash. The amount of solid waste disposed by oil palm mill industry to the environment can be reduced by using up this waste as replacement materials in producing oil palm shell lightweight aggregate concrete with the combination of palm oil fuel ash and $100 \%$ of oil palm shell. A systematic study on the utilization of ultrafine palm oil fuel ash as a pozzolanic admixtures in green ultrahigh performance fiber reinforced concrete was conducted by Aldahdooh et al. [45]. The study indicated that the optimum replacement of Ordinary Portland cement with ultrafine palm oil fuel ash was less than $25 \%$ in order to achieve desired compressive strength and agreed that the ultrafine palm oil fuel ash were able to be a good pozzolans in green ultrahigh performance fiber reinforced concrete with good engineering properties which can save the cost and contribute to sustainability in concrete industry. As well as the study of lightweight foam concrete incorporating palm oil fuel ash as filler investigated by Lim et al. [46] found the increment in compressive, tensile and flexural strength when $10 \%$ to $20 \%$ of palm oil fuel ash were replaced in the lightweight foamed concrete compared to sample with $100 \%$ of sand filler. 
Meanwhile, Muntohar and Rahman [47] made lightweight masonry block from palm oil kernel shell. The masonry block was made from a mixture of Portland cement, standard sand, and palm oil kernel shell and molded into $220 \mathrm{~mm} \times 110 \mathrm{~mm} \times 80 \mathrm{~mm}$ specimen size. It was found that the mixtures with same ratio of material produced highest compressive strength however, the compressive strength decreased when the proportion of palm oil kernel shell added to the mixtures increased. The masonry block produced with palm oil kernel shell met the requirement of class B2 and A2 for masonry as followed the building standards.

\section{Discussions}

In this paper, the discussion centered on usage of agricultural crop wastes in construction materials either as pozzolanic material, filler and fibres composites in different proportions and methods. Different tests were conducted on the product containing agricultural crop wastes by following the various standards to evaluate their properties, but the common performance measure evaluated by the researcher was the compressive strength. The review from different research has agreed that all agricultural wastes has good performance as construction materials whether increased or maintained the compressive strength of the final products. Compressive strength tests will provides the data on safety of the agricultural crop wastes usage in construction materials. In addition, the compressive strength tests will guarantee the quality of the construction materials containing agricultural crop wastes in order to meet specified requirement.

Nevertheless, there some standards and precautions should be followed during the processing of the agricultural crop wastes, for example, these wastes must undergoes various treatment process in which will affecting their effectiveness and properties as pozzolanic ash, fillers or fibre. Among examples of treatments that have been used were chemical treatment using acid solution (hydrocholric acid (HCL)) in which to reduce pottasium content in pozzolans [23, 25, 29], as well as using alkali solution (sodium hydroxide $(\mathrm{NaOH}))$ to treat fibres [26]. The pozzolanic activity of the treated materials has been increased, which increased the compressive strength of construction materials.

The effectiveness of agricultural waste materials also can be preserved through their heating temperature and durations of burning during calcination process and their particle size distribution. In this case, the correct burning procedure was important to produce pozzolanic ash containing amorphous silica with low carbon content [23]. In the context of pozzolanic ash, it was agreed that the finer particles were better in which it will increase the rate of reaction and gain in strength in final products. The finer particles also affected the water cement ratio, workability, creep and shrinkage properties of construction materials. The fineness of materials were depends on their grinding times, which also agreed either can decreased or increased the engineering properties of concrete. It was proved that the strength of concrete increased as the grinding time of RHA increased but then declined after reached the optimum value, as studied by Jaya et al. [48]. As all things considered, the compressive strength of the construction materials were depends on the effectiveness of the agricultural crop wastes used. Equally important, the original agricultural waste materials must be ensured to be free from any contaminants before using it in any product [49].

\section{Conclusions}

Overall, more research and efforts needs to be done on the environmental, economic, and technical aspects. The government policy related to waste recycling and sustainable development should be strictly implemented in order to promote application of agricultural 
crop waste materials in construction industries, which can brings this industries to a whole new level.

This research and paper was supported by Postgraduate Research Grantt (GPPS) of Office for Research, Innovation, Commercialization, Consultancy Management (ORICC) Universiti Tun Hussein Onn Malaysia (Project Vot Number U453).

\section{References}

[1] K.J. Mun, W.K. Hyoung, C.W. Lee, S.Y. So, and Y.S. Soh, Basic properties of nonsintering cement using phosphor gypsum and waste lime as activator, J. of Constr. Build. Mater., 21(6), 1342-1350 (2007)

[2] E. Aprianti, P. Shafigh, S. Bahri, and J. Nodeh, Supplementary cementitious materials origin from agricultural wastes - A review, Constr. Build. Mater., 74, 176-187 (2015)

[3] T. Vaisanen, A. Haapala, R. Lappalainen and L. Tomppo, Utilization of agricultural and forest industry waste and residues in natural fiber-polymer composites: A review, Waste Management, 54, 62-73 (2016)

[4] P. Shafigh, H. Mahmud, M.Z. Jumaat and M. Zargar, Agricultural wastes as aggregate in concrete mixtures - A review, Constr. Build. Mater., 53, 110-117 (2014)

[5] S. Raut, R. Ralegaonkar, and S. Mandavgane, Development of sustainable construction material using industrial and agricultural solid waste: A review of wastecreate bricks, Constr. Build. Mater., 25(10), 4037-4042 (2011)

[6] B. Wang, F. Dong, M. Chen, J. Zhu, J. Tan, X. Fu, Y. Wang and S. Chen, Advances in recycling and utilization of agricultural wastes in China: Based on environmental risk, crucial pathways, influencing factors, policy mechanism, Procedia Environmental Sciences, 31, 12-17 (2016)

[7] B.H.A. Bakar, P.J. Ramadhansyah and M.J.M. Azmi, Effects of rice husk ash fineness on the chemical and physical properties of concrete, Magazine of Concrete Research, 63(5), 313-320 (2011)

[8] E. Rafiee, S. Shahebrahimi, M. Feyzi and M. Shaterzadeh, Optimization of synthesis and characterization of nanosilica produced from rice husk (a common waste material), International Nano Letters; Springer Open J., 2(29) (2012)

[9] R.S. Bie, X.F Song, Q.Q. Liu, X.Y. Ji and P. Chen, Studies on effect of burning conditions and rice husk ash (RHA) blending amount on the mechanical behavior of cement, J. of Cem. and Concr. Compos., 55, 162-168 (2014)

[10] R. Jauberthie, F. Rendell, S. Tamba and I.Cisse, Origin of the pozzolanic effect of rice husks, Constr. Build. Mater., 14, 419-423 (2000)

[11] R.S. Bie, X.F Song, Q.Q. Liu, X.Y. Ji and P. Chen, Studies on effect of burning conditions and rice husk ash (RHA) blending amount on the mechanical behavior of cement, J. of Cem. and Concr. Compos., 55, 162-168 (2014)

[12] S.K. Antiohos, V.G. Papadakis, and S. Tsimas, Rice husk ash (RHA) effectiveness in cement and concrete as a function of reactive silica and fineness, Cem. and Concr. Research, 61-62, 20-27 (2014)

[13] C. Hwang, L.A. Bui and C. Chen, Effect of rice husk ash on the strength and durability characteristics of concrete, Constr. Build. Mater., 25(9), 3768-3772 (2011)

[14] S. Shahidan, I. Ismail, and N. Jamaluddin, A Review on Performance of Waste Materials in Self Compacting Concrete (SCC), J. of Technol. (Sciences \& Engineering), 78(4), 29-35 (2016)

[15] V. Vishwakarma, D. Ramachandran, N. Anbarasan, and A.M. Rabel, Studies of rice husk ash nanoparticles on the mechanical and microstructural properties of the concrete, Materials Today: Proceedings, 3(6), 1999-2007 (2016) 
[16] R. Zerbino, G. Giaccio, and G. Isaia, Concrete incorporating rice-husk ash without processing, Constr. Build. Mater., 25(1), 371-378 (2011)

[17] R. Kishore, V. Bhikshma and P. Jeevana Prakash, Study on strength characteristics of high strength rice husk ash concrete, Proc. Engineering, 14, 2666-2672 (2011)

[18] N.V. Tuan, G. Ye, K.V. Breugel, A.L.A. Fraaij, and B.D. Dai, The study of using rice husk ash to produce ultra-high performance concrete, Constr. Build. Mater., 25(4), 2030-2035 (2011)

[19] D. Chopra, R. Siddique and Kunal, Strength, permeability and microstructure of selfcompacting concrete containing rice husk, Biosystems Eng. J., 130, 72-80 (2015)

[20] S. Hesami, S. Ahmadi, and M. Nematzadeh, Effects of rice husk ash and fiber on mechanical properties of pervious concrete pavement, Constr. Build. Mater., 53, 680691 (2014)

[21] R.P. Jaya, M.R. Hainin, B.H. Abu Bakar, M.A. Megat Johari, M.H. Wan Ibrahim, and D.S. Jayanti, Strength and microstructure analysis of concrete containing rice husk ash under seawater attack by wetting and drying cycles, Advances in Cement Research, 26(3), 145-154 (2014)

[22] J. Sutas, A. Mana and L. Pitak, Effect of rice husk and rice husk ash to properties of bricks, Proc. Engineering, 32, 1061-1067 (2012)

[23] G. Cordeiro and C. Sales, Pozzolanic activity of elephant grass ash and its influence on the mechanical properties of concrete, Cem. and Concr. Compos., 55, 331-336 (2015)

[24] V. Strezov, T.J. Evans and C. Hayman, Thermal conversion of elephant grass (Pennisetum Purpureum Schum) to bio-gas, bio-oil and charcoal, Bioresour. Technol., 99, 8394-8399 (2008)

[25] E.Y. Nakanishi, M. Frias, S.M. Ramirez, S.F. Santos, M.S. Rodrigues, O. Rodriguez, and H. Savastano Jr, Characterization and properties of elephant grass ashes as supplementary cementing material in pozzolan $/ \mathrm{Ca}(\mathrm{OH})_{2}$ pastes, Constr. Build. Mater., 73, 391-398 (2014)

[26] M. Haameem J.A, M.S. Abdul Majid, M. Afendi, H.F.A. Marzuki, I. Fahmi, and A.G. Gibson, Mechanical properties of Napier grass fibre/polyester composites, J. of Composites Structures, 136, 1-10 (2016)

[27] K. Ramanaiah, A.V. Ratna Prasad and K. Hema Chandra Reddy, Thermo physical properties of elephant grass fiber-reinforced polyester composites, Materials Letters, 89, 156-158 (2012)

[28] M.J.M. Ridzuan, M.S. Abdul Majid, M. Afendi, S.N. Aqmariah Kanafiah, J.M. Zahri and A.G. Gibson, Characterisation of natural cellulosic fibre from Pennisetum purpureum stem as potential reinforcement of polymer composites, Mater. and Design, 89, 839-847 (2016)

[29] E.Y. Nakanishi, M. Frias, S.F. Santos, M.S. Rodrigues, R.V. Villa, O. Rodriguez and H.S. Junior, Investigating the possible usage of elephant grass ash to manufacture the eco-friendly binary cements, J. of Cleaner Prod., 116, 236-243 (2016)

[30] I. Merta and E.K. Tschegg, Fracture energy of natural fibre reinforced concrete, Constr. Build. Mater., 40, 991-997 (2013)

[31] J.C.B. Moraes, J.L. Akasaki, J.L.P. Melges, J. Monzó, M.V. Borrachero, L. Soriano, J. Payá and M.M. Tashima, Assessment of sugar cane straw ash (SCSA) as pozzolanic material in blended Portland cement: Microstructural characterization of pastes and mechanical strength of mortars, Constr. Build. Mater., 94, 670-677 (2015)

[32] S.M.S. Kazmi, S. Abbas, M.A. Saleem, M.J. Munir and A. Khitab, Manufacturing of sustainable clay bricks: Utilization of waste sugarcane bagasse and rice husk ashes, Constr. Build. Mater., 120, 29-41 (2016) 
[33] N. Ali, N.A. Zainal, M.K. Burhanudin, A.A.A. Samad, N. Mohamad, S. Shahidan and S.R. Abdullah, Physical and Mechanical Properties of Compressed Earth Brick (CEB) Containing Sugarcane Bagasse Ash, EDP Sciences, 47 (2016)

[34] M.M. Tashima, J.C.B. Moraes, J.L.P. Melges, J. Monzo, M.V. Borrachero, L. Soriano and J. Paya, Assessment of sugar cane straw ash (SCSA) as pozzolanic material in blended Portland cement: Microstructural characterization of pastes and mechanical strength of mortars, Constr. Build. Mater., 94, 670-677 (2015)

[35] S. Rukzon and P. Chindaprasirt, Utilization of bagasse ash in high-strength concrete, J. of Mater. and Des., 34, 45-50 (2012)

[36] A. Rerkpiboon, W. Tangchirapat and C. Jaturapitakkul, Strength, chloride resistance, and expansion of concretes containing ground bagasse ash, Constr. Build. Mater., 101, 983-989 (2015)

[37] P.O. Modani and M.R. Vyawahare, Utilization of Bagasse Ash as a Partial Replacement of Fine Aggregate in Concrete, Procedia Engineering, 51(NUiCONE 2012), 25-29 (2013)

[38] S. A. Lima, H. Varum, A. Sales, and V. F. Neto, Analysis of the mechanical properties of compressed earth block masonry using the sugarcane bagasse ash, Constr. Build. Mater., 35, 829-837 (2012)

[39] R. Alavez-Ramirez, P. Montes-Garcia, J. Martinez-Reyes, D.C. Altamirano-Juarez, and Y. Gochi-Ponce, The use of sugarcane bagasse ash and lime to improve the durability and mechanical properties of compacted soil blocks, Constr. Build. Mater., 34, 296-305 (2012)

[40] D. Mujah, Compressive strength and chloride resistance of grout containing ground palm oil fuel ash, J. of Cleaner Prod., 112, 712-722 (2016)

[41] M.R. Hamidian, P. Shafigh, M.Z. Jumaat, U.J. Alengaram and N.H.R. Sulong, A new sustainable composite column using an agricultural solid waste as aggregate, J. of Cleaner Prod., 129, 282-291 (2016)

[42] B. Alsubari, P. Shafigh and M. Z. Jumaat, Utilization of high-volume treated palm oil fuel ash to produce sustainable self-compacting concrete, J. of Cleaner Prod., 137, 982-996 (2016)

[43] W. Tangchirapat, C. Jaturapitakkul and P. Chindaprasirt, Use of palm oil fuel ash as a supplementary cementitious material for producing high-strength concrete, Constr. Build. Mater., 23, 2641-2646 (2009)

[44] K. Muthusamy, N. Zamri, M.A. Zubir, A. Kusbiantoro and S.W. Ahmad, Effect of mixing ingredient on compressive strength of oil palm shell lightweight aggregate concrete containing palm oil fuel ash, Procedia Engineering, 125, 804-810 (2015)

[45] M.A.A. Aldahdooh, N.M. Bunnori and M.A.M. Johari, Development of green ultrahigh performance fiber reinforced concrete containing ultrafine palm oil fuel ash, Constr. Build. Mater., 48, 379-389 (2013)

[46] S.K. Lim, C.S. Tan, O.Y. Lim and Y.L. Lee, Fresh and hardened properties of lightweight foamed concrete with palm oil fuel ash as filler, Constr. Build. Mater., 46, 39-47 (2013)

[47] A.S. Muntohar and M.E. Rahman, Lightweight masonry block from oil palm kernel shell, Constr. Build. Mater., 54, 477-484 (2014)

[48] R.P. Jaya, B.H. Abu Bakar, M.A. Megat Johari, M.H. Wan Ibrahim, Engineering properties of normal concrete Grade 40 containing rice husk ash at different grinding times, Int. J. of Technology, 1, 10-19 (2011)

[49] L. Zhang, Production of bricks from waste materials - A review, Constr. Build. Mater., 47, 643-655 (2013) 